\title{
Influence of Natural Lung Surfactant Inhalations on Clinical Symptoms and Pulmonary Function Parameters in Patients with Bronchial Asthma. Communication 1
}

\author{
O.V. Stepanova ${ }^{1}$; E.A. Akulova ${ }^{1}$; A.A. Kochneva ${ }^{1}$; A.A. Seiliev, $\mathrm{PhD}^{2}$; A.Ed. Shulga ${ }^{2}$; \\ O.V. Lovacheva, $\mathrm{PhD}, \mathrm{ScD}^{3}$; S.A. Lukyanov, $\mathrm{PhD}^{1}$; K.G. Shapovalov, $\mathrm{PhD}, \mathrm{ScD}^{1}$; \\ V.A. Volchkov, $\mathrm{PhD}, \mathrm{ScD}^{2}$; O.A. Rosenberg, $\mathrm{PhD}, \mathrm{ScD}^{2 *}$ \\ ${ }^{1}$ Chita State Medical Academy of Ministry of Health, Chita, Russia \\ ${ }^{2}$ Russian Research Center of Radiology and Surgery Technologies, St. Petersburg, Russia \\ ${ }^{3}$ Central Tuberculosis Research Institute, Moscow, Russia
}

\begin{abstract}
Background: Damage to lung surfactant (LS) enabling the lung local immunity may contribute to the development of bronchial inflammation in patients with bronchial asthma.

Methods and Results: A 40-day course of 16 LS (Surfactant-BL) inhalations at the dose of $25 \mathrm{mg}$ was added to inhaled corticosteroids (ICS) and short/long-acting bronchodilators or combined inhalers in 14 patients with bronchial asthma. After 7 inhalations, patients demonstrated a significant decrease in shortness of breath and bronchospasm attacks, double reduction of ICS dose $(p=0.01)$, and improvement of pulmonary function. Forced vital capacity (FVC) increases during treatment in a linear fashion $(y=62.9+5.60 \cdot x ; p<0.05)$, reaching the normal level (80\%) after 9 inhalations (Day 15). Forced expiratory volume (FEV1) increases in a linear fashion $(y=50.7+4.15 \cdot x ; p<0.05)$ without reaching the normal level $(80 \%)$ after 16 inhalations (Day 41). The FEV1/FVC ratio does not change significantly in the time period between Day 1 to Day 15. By Day 41 the value decreases significantly to $67.4 \pm 4.66 \%(p<0.05)$. The peak expiratory flow (PEF) parameter increases in a linear fashion $(y=53.9+5.00 \cdot x$; $p<0.01$ ) from $57.7 \pm 6.33 \%$ to $76.2 \pm 9.33 \%$ of the predicted value.

Conclusion: LS inhalations improve the condition of patients with bronchial asthma, allow ICS dose reduction by 2 times, and improve pulmonary function parameters. (Int J Biomed. 2016; 6(4):255-258.)
\end{abstract}

Key Words: lung surfactant $\bullet$ bronchial asthma $\bullet$ inhaled corticosteroids $\bullet$ dose $\bullet$ pulmonary function

\section{Introduction}

Conventional treatments for bronchial asthma (BA), such as inhaled corticosteroids (ICS) and short-term and longterm bronchodilators, are aimed at preventing bronchospasm episodes rather than restoring the structure and functions of the bronchial epithelium. Even though this kind of therapy significantly improves patients' quality of life, upon termination of daily medicine taking, bronchospasm episodes recur often with increased frequency and severity. In some patients long-

*Corresponding author: Prof. Oleg Rosenberg, $M D, P h D$ ScD Department of Medical Biotechnology of Russian Research Center of Radiology and Surgery Technologies, St. Petersburg, Russia.E-mail: rozenberg@biosurf.ru term ICS use is accompanied by such complications as oral and oropharyngeal candidosis, dysphonia, and cough, which cause considerable discomfort. High doses of ICS equivalent to $1000 \mathrm{mcg}$ of fluticasone propionate are accompanied by such complications as pneumonia, glaucoma, cataract, adrenal function suppression, osteoporosis, and diabetes. ${ }^{[1]}$

The evidence from our earlier work that long-term ICS in rats significantly decreases the LS content has led us to hypothesize that natural LS formulations may decrease patient dependency on ICS. ${ }^{[2]}$ Deficiency or qualitative changes in LS are found in many lung conditions, including BA. ${ }^{[3,4]}$ Apart from enabling the breathing mechanism, LS is known to provide molecular mechanisms of innate and adaptive lung tissue immunity and to have anti-inflammatory properties. ${ }^{[5,6]}$ Although almost no research has been carried out so far to 
investigate the possibility of restoring pulmonary function in BA patients by inhaled LS formulations, the role of LS system impairment and the possible use of LS formulations for BA have been discussed in detail in the review by Hohlfeld. ${ }^{[7]}$

The objective of the study was to investigate the influence of inhaled natural LS formulation on the clinical manifestations and the dynamics of pulmonary function parameters in patients with partly controlled and uncontrolled persistent BA as well as to assess the feasibility of ICS stepdown.

\section{Methods}

We examined 14 BA patients with partly controlled and uncontrolled persistent BA at the Pulmonary Centre of the Chita Road Clinical Hospital. The trial was carried out based on the approval of the Local Ethical Committee under Chita State Medical Academy of the Ministry of Health of the Russian Federation according to approved Protocol. The enrolled patients were diagnosed according to the 2016 GINA guidelines and had had a history of asthma for a period of time varying from 6 months to 24 years. ${ }^{[8]}$ The treatment they had been receiving prior to their entry into the study included antibiotics during exacerbations, with 8 out of the 14 patients receiving short courses of systemic per-oral and/ or intravenous glucocorticoids. After their condition became stable, they had received either inhaled ICS and short/longacting bronchodilators or combined inhalers for 12 months to 12 years prior to enrollment. Upon enrollment the patients started a course of inhalations with Surfactant-BL (OOO Biosurf, Saint Petersburg, Russia), a natural LS formulation, given as add-on therapy. The surfactant was administered using the compressor nebulizer Boreal (Italy). The patients were instructed how to use it at the first visit (V1) and then continued to use it on their own for inhalations at home. The surfactant was taken daily at the dose of $25 \mathrm{mg}$ for the first 7 days of the study and then at Days 10,13, 16, 19, 22, 26, 30, 35 and 40 (a total of 16 inhalations), so that the intervals between inhalations were gradually increased. Patients were examined at 5 visits on Days 1(V1), 8(V2), 15(V3), 29(V4) and 41(V5). At each of the 5 visits the frequency of bronchospasm episodes, shortness of breath with exercise and speaking and frequency of attacks while sleeping were registered. For pulmonary function assessment, a spirometer MAC-1, VISMA-Planar (Belarus), and the computer software SpiroExpert were used. During the examination, 3-8 technically acceptable maneuvers were used to achieve result reproducibility based on the following criteria:

the difference between two highest $\mathrm{FVC}$ values $\leq 150 \mathrm{ml}$;

the difference between two highest FEV1 values $\leq 150 \mathrm{ml}$;

(for absolute $\mathrm{FVC}$ values $<=1 \mathrm{~L}$ with allowable differences between maneuvers not exceeding $100 \mathrm{ml}) \cdot{ }^{[9,10,11]}$

Lung function was assessed based on spirometric measurements: FVC - forced vital capacity (L), FEV1forced expiratory volume in 1 second (L), FEV1/FVC ratio $(\%)$, and PEF - peak expiratory flow $(\mathrm{L} / \mathrm{s})$. The values of the above parameters were specified as a percent of the predicted value. ${ }^{[9]}$
Statistical analysis was performed using the statistical software «Statistica» (v6.0, StatSoft, USA). The mean (M) and standard error of the mean (SEM) were calculated. Student's unpaired and paired t-tests were used to compare average values for data with normal distribution. Regression analysis was performed by the least squares method. The statistical significance of the $b$ coefficients of the linear regression equations was evaluated using Student's t-tests. For evaluating the statistical significance of changes in patient condition registered on the basis of their complaints as well as ICS dose reduction or termination non-parametric Z-tests were used. A probability value of $p<0.05$ was considered statistically significant.

\section{Results}

Of 14 patients, 13 showed resolution of wheezing, decrease of frequency or resolution of attacks, and resolution of shortness of breath and bronchospasm episodes with moderate exercise (such as climbing upstairs to the first or second floor) since their V2. One patient of 14 suffered from asthma night attacks and his attacks stopped. Dynamics of patient complaints show statistically significant $(p=0.01)$ differences of BA clinical manifestation frequency between baseline and after 7 inhalations of the formulation. In 11 (78.6\%) out of 14 patients the ICS dose was halved, and in 1 (7.1\%) patient ICS was later terminated. In 3 patients no significant ICS dose reduction could be achieved. Statistical analysis showed significant frequency of ICS dose reduction due to surfactant-BL inhalations $(p=0.01)$.

Looking at the changes in pulmonary function parameters (Figure 1), it should be noted that FVC increases during treatment in a linear fashion $(y=62.9+5.60 \cdot x ; p<0.05)$, reaching the normal level $(80 \%)$ by V3 after 9 inhalations of Surfactant-BL. FEV1, the most important parameter of pulmonary function showing the severity of bronchial obstruction in BA, increases during treatment in a linear fashion $(y=50.7+4.15 \cdot x ; p<0.05)$ without reaching the normal level $(80 \%)$ by V5.
FVC

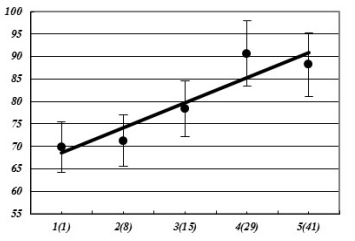

FEV1/FVC

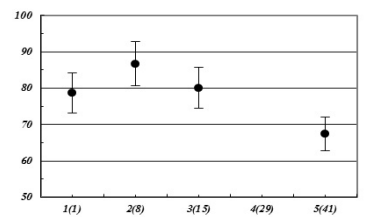

FEV1

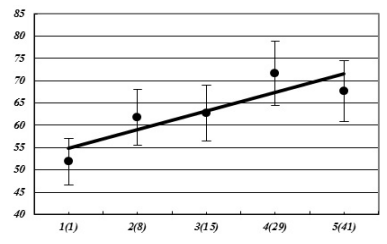

PEF

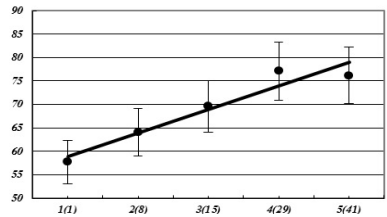

Fig. 1. Dynamics of pulmonary function parameters $X$-axis - the number of visit (day of visit); $Y$-axis - $\%$ from the predicted value; points with confidence interval - $x \pm 2 \mathrm{~m}$; - lines of linear regression equations 
The FEV1/FVC ratio does not change significantly in the time period between $\mathrm{V} 1$ and $\mathrm{V} 3$ staying at the mean value of $81.8 \pm 2.82 \%$. However, by V5 the value decreases significantly to $67.4 \pm 4.66 \%(p<0.05)$. The PEF parameter showing resistance to airflow in the airways (Figure 1) increases during treatment in a linear fashion $(y=53.9+5.00 \cdot x$; $p<0.01)$ ) from $57.7 \pm 6.33 \%$ of the predicted value (V1) to $76.2 \pm 9.33 \%$ of the predicted value (V5), which suggests a decrease in resistance to airflow in the airways.

Thus, clinical evidence and pulmonary function parameters from patients with partly controlled and uncontrolled persistent $\mathrm{BA}$ who had received 16 inhalations of natural LS at the dose of $25 \mathrm{mg}$ as add-on therapy to ICS and short/long-acting bronchodilators suggests a positive effect of surfactant therapy as part of combined therapy. As a result of this therapy, many patients reported lower frequency of asthma attacks, resolution or lower frequency of bronchospasm episodes with moderate exercise, and termination (1 patient) or double reduction of the ICS dose (10 patients out of 14). Another important result is that the objective evidence from changes in pulmonary function parameters showed significant functional improvement in the bronchi condition.

\section{Discussion}

Experiments on sensitized mice and guinea pigs showed prevention of bronchospasm in response to an antigen provocation following LS administration. ${ }^{[12]}$ Improvement of pulmonary function due to LS administration has also been shown in human patients with BA in several studies. Babu et al. ${ }^{[13]}$ demonstrated the feasibility of stopping early response to antigen provocation in atopic BA and increased FEV1 due to Pumactant inhalations. Kurashima et al., ${ }^{[14]}$ in a doubleblind, placebo-controlled study of 12 patients with BA, registered a significant increase of FEV, FEV1 and MMF 20 minutes after administering $10 \mathrm{mg}$ of surfactant formulation. Zagorulko et al. ${ }^{[15]}$ showed that one time intratracheal administration of Suzakrin at the dose of $500 \mathrm{mg}$ improves lung function parameters and normalizes LS phospholipid composition in children with BA. However no study has been carried out so far that would include BA treatment with LS formulations and register the dynamics of patient clinical status. Neither have there been any attempts to register the feasibility of ICS reduction due to surfactant therapy. It should be mentioned that multiple administration of 'empty' liposomes from phosphatidylcholine and cholesterol to rats ${ }^{[16]}$ and multiple administarion of LS to newborns ${ }^{[17]}$ enhances the synthesis of endogenous surfactant by its reutilization by the alveolocytes-II ${ }^{[6]}$ Furthermore, the effectiveness of surfactant therapy in adults has been shown in a number of studies on acute respiratory distress syndrome ${ }^{[18-20]}$ and discussed in depth in reviews by Rosenberg et al. ${ }^{[6,21]}$ It should be noted that long-term courses of Sufactant-BL inhalations have been used before, for lung tuberculosis (TB). ${ }^{[22]}$ The authors drew on the known evidence from surfactant system pathology in lung TB. ${ }^{[23]}$ Adding surfactant inhalations to the standard anti-TB treatment scheme that includes chemotherapy and antibiotics resulted in significant resolution of lung infiltrations and foci in patients who had shown no positive X-ray dynamics to standard therapy during 3 months. In this study, 2 months after cessation of surfactant therapy $85 \%$ of patients showed bacillary elimination in the sputum (compared to $63 \%$ in control), over $90 \%$ of patients (compared to $61 \%$ in control) showed resolution or significant decrease of infiltrations, and $71 \%$ of patients (compared to $43 \%$ in control) showed closure of caverns up to $3 \mathrm{~cm}$ in diameter. Another study of surfactant therapy in lung TB yielded similar results, demonstrating a decrease of large caverns from 5 to $8 \mathrm{~cm}$ in diameter by 2-12 times. ${ }^{[24]}$

Therefore, we believe that the results of surfactant therapy given as 16 inhalations over 41 days as part of combined therapy of patients with BA, which included positive dynamics of clinical manifestations, high frequency of ICS dose reduction by half, and improved lung function parameters, are promising and can become a rationale for expanding this clinical trial.

\section{Competing interests}

The authors declare that they have no conflict of interest.

\section{Acknowledgments}

We thank Evgenia Zvonareva for technical assistance and translation of the manuscript into English.

\section{References}

1. Kelly HW, Nelson HS. Potential adverse effects of the inhaled corticosteroids. J Allergy Clin Immunol. 2003; 112(3):469-78.

2. Rosenberg OA, Lebedeva ES, Loshakova LV, Shulga AEd, Seiliev AA, Volchkov VA. Influence of Long-Term Inhaled Glucocorticoids on the Lung Surfactant Phospholipid Levels in Rats. Int J Biomed. 2016; 6(3):167-69.

3. Kurashima K, Fujimura M, Matsuda T, Kobayashi T. Surface activity of sputum from acute asthmatic patients. Am J Respir Crit Care Med. 1997; 155(4):1254-9.

4. Devendra G., Spragg RG. Lung surfactant in subacute pulmonary disease. Respir Res. 2002; 3:19.

5. van Iwaarden FJ, van Golde LMJ. Pulmonary surfactant and lung defense. In: Robertson B, Taeusch HW, editors. Surfactant therapy for lung disease. Lung biology in health and disease. Vol. 84. New York: Marcel Dekker Inc; 1995:75-84.

6. Rozenberg OA. Pulmonary Surfactants for Acute and Chronic Lung Diseases (Part II). Gen Reanimatol. 2014; 10(5):69-86.

7. Hohlfeld JM. The role of surfactant in asthma. Respir Res. $2002 ; 3: 4$

8. A Pocket Guide for Physicians and Nurses Updates 2015. Retrieved from ginasthma.org/wp-content/uploads/.../GINA_ Pocket_2015.p

9. Quanjer PH, Tammeling GJ, Cotes JE, Pedersen OF, Peslin R, Yernault JC. Lung volumes and forced ventilatory flows. Report Working Party Standardization of Lung Function Tests, European Community for Steel and Coal. Official Statement of the European Respiratory Society. Eur. Resp J Suppl. 1993; 16:5-40. 
10. Miller MR1, Hankinson J, Brusasco V, Burgos F, Casaburi R, Coates A, et al.; ATS/ERS Task Force. Standardisation of spirometry. Eur Respir J. 2015, 26(2):319-38.

11. Federal Clinical Recommendations on the Use of Spirometric Method. 2013; Retrieved from http://spulmo.ru/ download/spirometry.doc.

12. Cheng G, Ueda T, Sugiyama K, Toda M, Fukuda T. Compositional and functional changes of pulmonary surfactant in a guinea-pig model of chronic asthma. Respir Med. 2001; 95(3):180-6.

13. Babu KS , Woodcock DA, Smith SE, Staniforth JN, Holgate ST, Conway JH. Inhaled synthetic surfactant abolishes the early allergen-induced response in asthma. Eur Respir J. 2003; 21(6):1046-9.

14. Kurashima K, Ogawa H, Ohka T, Fujimura M, Matsuda T, Kobayashi T. A pilot study of surfactant inhalation in the treatment of asthmatic attack. Arerugi. 1991;40(2):160-3.

15. Zagorul'ko AK, Nikitina NV, Askari TA, Zagorul'ko AA. Role of the pulmonary surfactant in the pathogenesis of bronchial asthma. Lik Sprava. 2001;(5-6):16-9. [Article in Russian].

16. Rosenberg OA, Kirillov YA, Danilov LN, Loshakova LV, Lebedeva ES, Shylga AE et al. The lung surfactant immune system response to intratracheal administration of "empty" liposomes. J Liposome Research. 1994; 4(1):203-212.

17. Soll R, Ozek E. Multiple versus single doses of exogenous surfactant for the prevention or treatment of neonatal respiratory distress syndrome. Cochrane Database Syst Rev. 2009; 1: CD000141.
18. Gregory TJ, Steinberg KP, Spragg R, Gadek JE, Hyers TM, Longmore WJ et al. Bovine surfactant therapy for patients with acute respiratory distress syndrome. Am J Respir Crit Care Med. 1997; 155(4):1309-15.

19. Rosenberg OA, Bautin AE, Osovskich VV, Tsibulkin EK, Gavrilin SV., Kozlov IA. When to start surfactant therapy (ST therapy) of acute lung injury? Abstracts 11th ERS Annual Congress Berlin, Germany. September 22-26, 2001. Eur Respir J. 2001; 18 (Suppl 38): P153, 7s.

20. Bautin A, Khubulava G, Kozlov I, Poptzov V, Osovskikh V, Seiliev A, et al. Surfactant Therapy for Patients with ARDS after Cardiac Surgery. J Liposome Research. 2006; 16(3): 265-72.

21. Rosenberg O, Seiliev A, Zhuikov A. Lung surfactant: correlation between biophysical characteristics, composition, and therapeutic efficacy. In: Gregoriadis G., editor. Liposome Technology. New York: Informa Healthcare; 2006:317-345.

22. Lovacheva OV, Chemichenko NV, Lepekha LN, Erokhin $\mathrm{VV}$, Rosenberg OA. Use of surfactant-BL (S-BL) in complex treatment of pulmonary TB patients. ERJ. 2003; 22, Suppl. 45, P3250, 521s.

23. Erokhin VV, Romanova LK. Lung Surfactant System. In: Erokhin VV, Romanova LK, editors. Lung Cell Biology in Health and Pathology. Doctors' Handbook. Moscow: Medicine; 2000:167-181. [Handbook in Russian].

24. Zhemkov VF, Ivanovsky VB, Zhemkova MV, Seiliev AA, Volchkov VA, Rosenberg OA. Use of natural lung surfactant in the combination treatment of pulmonary tuberculosis. Tuberculosis and Lung Diseases. 2013;91(2):18-22. [Article in Russian]. 